
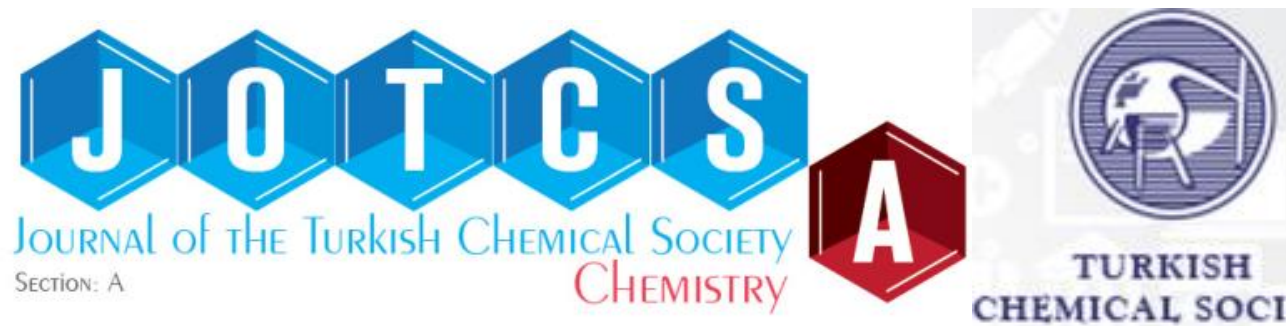

TURKISH

CHEMICAL SOCIETY

\title{
NANO ZINC BORATE AS A LUBRICANT ADDITIVE
}

\author{
Sevdiye Atakul Savrik¹, Burcu Alp ${ }^{1}$, Fatma Ustun'1, Devrim Balkose ${ }^{1, a}$ \\ 1 İzmir Institute of Technology Department of Chemical Engineering \\ Gulbahce Urla Izmir Turkey
}

(This article first appeared in PPM2017 and was accepted as a non-peer-reviewed manuscript to be published in JOTCSA)

\begin{abstract}
Lubricants consist of base oils and chemical additives such as dispersants, surfactants, oxidation inhibitors, and antiwear agents. Organic and inorganic boron-based additives increase wear resistance and decreases friction. Hexagonal boron nitride and metal borates are used for this purpose. Zinc borate is a synthetic hydrated metal borate. The production techniques of zinc borate generally include the reaction between zinc source materials (zinc oxide, zinc salts, zinc hydroxide) and the boron source materials (boric acid and borax). The nano zinc borate particles were prepared from zinc nitrate and borax in the present study by using low initial zinc and borate concentrations and low temperature to prevent particle growth. The templates span 60 and PEG 4000 were used to control the particle size. The particles were separated from mother liquor by centrifugation, washed with ethanol, dried and ground and used as additive to base oil. The particles have $\mathrm{H}_{2} \mathrm{O}$ and $\mathrm{B}(3)-\mathrm{O}$ vibrations in their FIIR spectra. The empirical formula of the nanoparticles was approximately $3 \mathrm{ZnO} .2 \mathrm{~B}_{2} \mathrm{O}_{3} .4 \mathrm{H}_{2} \mathrm{O}$ from EDX and TGA analysis. X-ray diffraction diagram indicated the particles were in amorphous state. When the nanoparticles were added to light neutral oil the wear scar diameter and friction coefficient was lowered $50 \%$ and $20 \%$ respectively.
\end{abstract}

Keywords: Base oil, nano zinc borate, lubricant additive.

Cite this: Atakul Savrik S, Alp B, Ustun F, Balkose D. NANO ZINC BORATE AS A LUBRICANT ADDITIVE. JOTCSA. 2017;5(sp. is. 1):45-52.

*Corresponding author. E-mail: devrimbalkose@gmail.com. 
Atakul Savrik S, Alp B, Ustun F, Balkose D. JOTCSA. 2017; 5(sp. is. 1); 45-52. RESEARCH ARTICLE

\section{INTRODUCTION}

Numerous studies have been carried out in recent years on the effects of various metal borate particles as lubricating oil additives on wear and friction [Hu and Dong, 1998; Hu et al., 2000]. Their effectiveness can be related to the formation of a borate glass as a tribochemical film or the deposition of particles on the rubbing surface [Varlot et al., 2001]. The friction reduction and anti-wear behaviors are dependent on the characteristics of nanoparticles, such as size, shape, and concentration.

Zinc borate is a synthetic hydrated metal borate. There are various kinds of crystalline hydrated zinc borate. In these products, $\mathrm{B}_{2} \mathrm{O}_{3} / \mathrm{ZnO}$ mole ratios change from 0.25 to 5 and it determines the characteristics of product. The production techniques of zinc borate generally include the reaction between zinc source materials (zinc oxide, zinc salts, zinc hydroxide) and the boron source materials (boric acid and borax) [Eltepe et al., 2007].

Nanoparticles of zinc borate are a requirement for their use a lubricant additive. Synthesis of nano particles of zinc borate in inverse emulsions in lubricating oil was possible [Savrik et al, 2011]. Nanoparticle formation by supercritical carbon dioxide $\left(\mathrm{CO}_{2}\right)$ drying of zinc borate species was investigated to evaluate possible chemical modifications in the product during the drying [Gonen et al, 2010 ]. Nanometer crystal zinc borate with a particle size of 20-50 nm was prepared using the ethanol supercritical fluid drying technique [Dong and $\mathrm{Hu}, 1998$ ]. Supercritical ethanol drying of zinc borate species to obtain nanoparticles was also investigated by Gonen et al [2011]. It was found that from zinc borates, zinc oxide and boric acid were formed [Gonen et al, 2011]. A nano-flake-like zinc borate $2 \mathrm{ZnO} .2 \mathrm{~B}_{2} \mathrm{O}_{3} .3 \mathrm{H}_{2} \mathrm{O}$ was prepared via coordination of homogeneous precipitation method using ammonia, zinc nitrate and borax as raw materials [Ting et al, 2009]. The crystal and hydrophobic zinc borate $\mathrm{Zn}_{2} \mathrm{~B}_{6} \mathrm{O}_{11} \cdot \mathrm{H}_{2} \mathrm{O}$ nanodiscs and nanoplatelets were successfully prepared by a wet method using $\mathrm{Na}_{2} \mathrm{~B}_{4} \mathrm{O}_{7} .10 \mathrm{H}_{2} \mathrm{O}$ and $\mathrm{ZnSO} 4.7 \mathrm{H}_{2} \mathrm{O}$ as raw materials in situ aqueous solution, and oleic acid as the modifying agent. It had been found that the as-prepared materials displayed nanodisc morphology with average diameters from 100 to $500 \mathrm{~nm}$ and the thicknesses about $30 \mathrm{~nm}$ [Tian et al, 2006].

The production and characterization of nano particles of hyrated zinc borate for lubrication was aimed at in the present study. Dilute solutions of borax and zinc nitrate were mixed instantly at room temperature to avoid particle growth and hydrosols were formed. The particles were separated by centrifugation and washed with ethanol and dried at $25{ }^{\circ} \mathrm{C}$ under vacuum. 


\section{EXPERIMENTAL}

Anhydrous borax (Sigma Aldrich), zinc nitrate hexahydrate $\left(\mathrm{Zn}\left(\mathrm{NO}_{3}\right)_{2} .6 \mathrm{H}_{2} \mathrm{O}\right)$ (Sigma-Aldrich), light neutral oil (TUPRAŞ A.Ş), and sorbitan monostearate (Span 60, Sigma-Aldrich), PEG 4000 (Merck) were used in the preparation of hydrated zinc borate nanoparticles and lubricants.

$50 \mathrm{~cm}^{3}$ of $0.1 \mathrm{~mol} \mathrm{dm}^{-3}$ sodium borate solution was added instantly to $50 \mathrm{~cm}^{3}$ of $0.1 \mathrm{~mol} \mathrm{dm}^{-3}$ zinc nitrate solution and mixed at $600 \mathrm{rpm}$ for 2 hours at ambient temperature of $23{ }^{\circ} \mathrm{C}$. Experiments were repeated by adding $1 \mathrm{~cm}^{3}$ of $0.002 \mathrm{M}$ span 60 and $1 \mathrm{~cm}^{3}$ of $0.4 \mathrm{~g}$ PEG 4000 in $100 \mathrm{~cm}^{3}$ to the mixtures. While hydrosols have been mixed, their temperature and $\mathrm{pH}$ values were recorded. Since the particles passed through the Whatman filter paper, they were separated form the aqueous phase by centrifugation. They were separated by centrifugation using Rotofix 32 centrifuge at $2000 \mathrm{rpm}$ for 10 minutes, washed with ethanol and centrifuged again at $2000 \mathrm{rpm}$ for 10 minutes. The gelatinous precipitates were dried under vacuum at 10 $\mathrm{kPa}$ for 18 hours at $25^{\circ} \mathrm{C}$ to obtain nanoparticles. Since the nanoparticles were in an agglomerated state they were ground in a porcelain mortar and pestle before use.

The morphologies of the samples were examined using QUANTA 250F Scanning Electron Microscope (SEM). EDX analysis was carried out using the same instrument. The particle size of the powders were measured by Malvern 2000 zetasizer. X-ray diffraction diagrams were obtained by Phillips X'pert pro X-ray diffractometer employing Ni-filtered $\mathrm{Cu}$ Ka radiation. FTIR spectra of the samples were taken with SHIMADZU FTIR-8400S using $\mathrm{KBr}$ disc technique. TG analysis was performed by using SETARAM labsys TGA to determine changes in weight with heating under nitrogen flow at $40 \mathrm{~cm}^{3} \mathrm{~min}^{-1}$ rate and at a heating rate of $10^{\circ} \mathrm{C} \mathrm{min} \mathrm{m}^{-1}$ up to 600 ${ }^{\circ} \mathrm{C}$.

$25 \mathrm{~cm}^{3}$ of light neutral oil, $0.25 \mathrm{~g}$ of Span 60 and $0.25 \mathrm{~g}$ of the nanoparticles of zinc borate with Span 60 were mixed thoroughly at $600 \mathrm{rpm}$ rate and at $160{ }^{\circ} \mathrm{C}$ for one hour on a magnetic hot plate (Ika RH Digital KT/C) and left to cool down to room temperature by continuous stirring. A four ball tester (Ducom) was used to determine the friction coefficient and wear scar diameter. The tests were performed according to ASTM D 4172-94 at $392 \mathrm{~N}$ and the test duration was $1 \mathrm{~h}$ at $75^{\circ} \mathrm{C}$. The upper ball was rotated at $1200 \mathrm{rpm}$. Test balls were made from AISI standard steel No. E-52100 and had $12.7 \mathrm{~mm}$ diameter. Microphotographs of the wear scars of the three fixed and one rotating test balls were taken by using Olympos BX 60 equipped with Canon Powershot 590IS camera.

The visible spectrum of base oil separated by centrifugation from base oil was taken by using Perkin Elmer UV-Vis spectrophotometer by using base oil without any additive as thereference. 
Atakul Savrik S, Alp B, Ustun F, Balkose D. JOTCSA. 2017; 5(sp. is. 1); 45-52. RESEARCH ARTICLE

\section{RESULTS AND DISCUSSION}

\section{Reaction of aqueous borax and zinc nitrate solutions}

The zinc borate precipitation reaction is expected to occur as given in Equation 1

$(y / 2) \mathrm{B}_{4} \mathrm{O}_{7}^{2-}(\mathrm{aq})+x \mathrm{Zn}^{2+}(\mathrm{aq})+\mathrm{zH}_{2} \mathrm{O} \rightarrow \mathrm{xZnO} \cdot \mathrm{yB}_{2} \mathrm{O}_{3} \cdot \mathrm{zH}_{2} \mathrm{O}(\mathrm{s})($ Eq. 1)

There are other simultaneous reactions in the reaction medium, such as

$$
\begin{gathered}
2 \mathrm{Zn}^{2+}(\mathrm{aq})+3 \mathrm{OH}^{-}(\mathrm{aq})+\mathrm{NO}_{3}^{-}(\mathrm{aq}) \rightarrow \mathrm{Zn}_{2}(\mathrm{OH})_{3}(\mathrm{NO})_{3}(\mathrm{~s}) \\
\mathrm{Zn}^{2+}(\mathrm{aq})+2 \mathrm{OH}^{-}(\mathrm{aq}) \rightarrow \mathrm{Zn}(\mathrm{OH})_{2}(\mathrm{~s})
\end{gathered}
$$

\section{Functional groups by FTIR spectroscopy and TG analysis}

The FTIR spectra of the samples without any template and with templates span 60 and PEG 4000 are very similar to each other as seen in Figure 1 . There is a broad peak at $3358 \mathrm{~cm}^{-1}$ due to hydrogen-bonded $\mathrm{O}-\mathrm{H}$ group vibrations. Asymmetric $\mathrm{B}(3)-\mathrm{O}$ vibrations were observed at $1383 \mathrm{~cm}^{-1}$ and at $1350 \mathrm{~cm}^{-1}$. $\mathrm{H}-\mathrm{O}-\mathrm{H}$ bending vibration was observed at $1624 \mathrm{~cm}^{-1}$. At 1014 $\mathrm{cm}^{-1}$ a peak for symmetric $\mathrm{B}(3)-\mathrm{O}$ vibration was present. Out of plane bending vibration of $\mathrm{B}(3)-\mathrm{O}$ gave a small peak at $694 \mathrm{~cm}^{-1}$.

TG curves of the samples were very similar to each other as depicted in Figure 2.

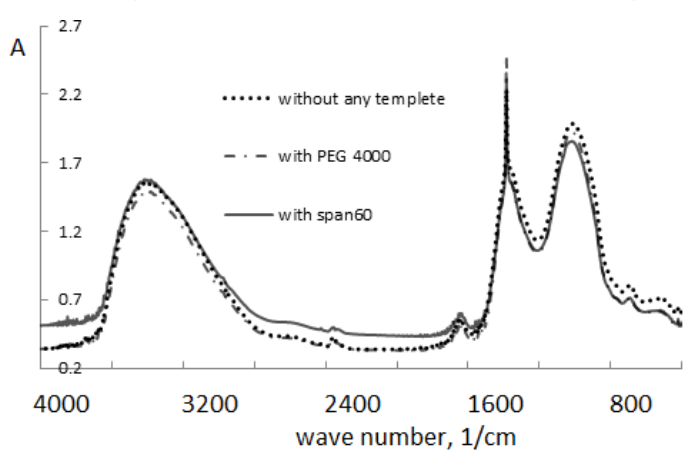

Figure 1: FTIR spectra of the zinc borates.

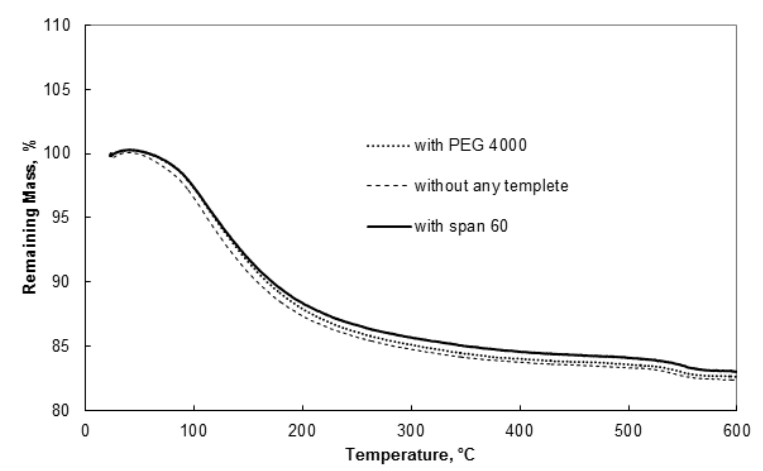

Figure 2: TG curves of the zinc borates. 
Atakul Savrik S, Alp B, Ustun F, Balkose D. JOTCSA. 2017; 5(sp. is. 1); 45-52. RESEARCH ARTICLE

On heating the samples only water is eliminated from the samples. All the samples contained very similar amount of water, around $17 \%$. The total amount of water was less than the zinc borate samples prepared from at higher initial borax and zinc nitrate concentrations. Savrik [2010] has determined the samples prepared at $70^{\circ} \mathrm{C}$ from $1 \mathrm{~mol} \mathrm{dm}^{-3}$ initial concentration contained around $20.6 \%$ water with the same FTIR spectra of the samples in the present study.

\section{Chemical Analysis by Energy Dispersive X-ray Spectroscopy (EDX)}

The energy dispersive spectroscopy was used to determine the elemental composition of zinc borates.The EDX spectrum of the samples are very similar for each zinc borate. The EDX spectrum of zinc borate with span 60 template is seen in Figure 3.

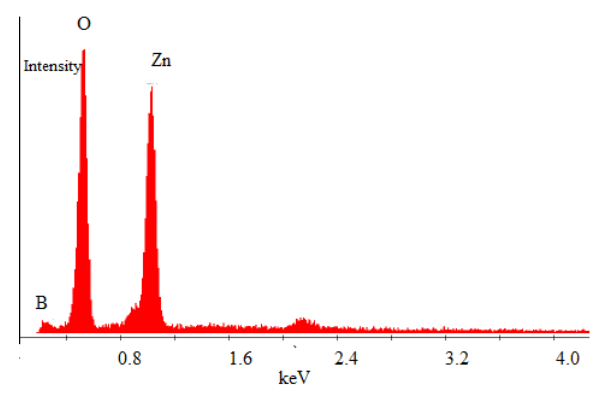

Figure 3: EDX spectrum of the zinc borate with span 60.

The chemical composition of the samples are similar to each other. The empirical formula of the nanoparticles was approximately $3 \mathrm{ZnO} \cdot 2 \mathrm{~B}_{2} \mathrm{O}_{3} .4 \mathrm{H}_{2} \mathrm{O}$ from EDX analysis. However it could be a mixture of zinc borate and zinc hydroxide due to parallel reactions.

\section{Morphologies of the powders}

The SEM micrographs of the dried samples are shown in Figure 4. The dried powders consisted of agglomerates of primary particles of $40 \mathrm{~nm}, 50 \mathrm{~nm}$ and $80 \mathrm{~nm}$ for samples without template, with span 60 and with PEG 4000 respectively. The particles were attracted to each other due to cappillary forces during drying. Water in the wet samples was replaced with ethanol which has a lower surface tension to decrease the attractive forces between the particles due to capillarity. However they were also agglomerated even drying of the ethanolic hydrogel.

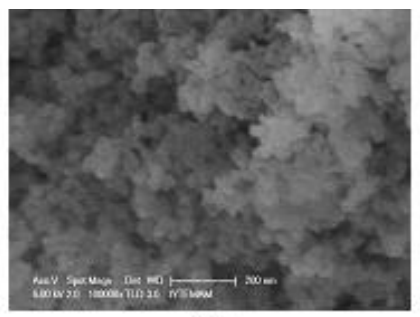

(a)

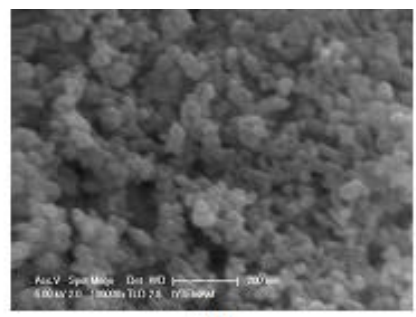

(b)

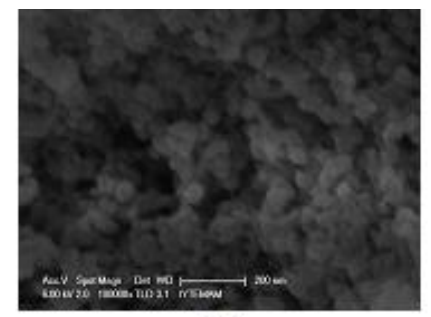

(c)

Figure 4: SEM micrograph of the sample a. without template b. with span 60 c. with PEG 4000. 


\section{Particle Size Distribution of the initially formed hydrated zinc borates in solution}

The size distribution of particles were monodisperse with number average sizes of $35.3 \mathrm{~nm}$ and $234 \mathrm{~nm}$ respectively for zinc borates without any template and with span 60 respectively. However the particle size distribution of particles with PEG 4000 were bidisperse, the average size was $228.5 \mathrm{~nm}$ and $969.7 \mathrm{~nm}$ for $94.6 \%$ and $5.4 \%$ of the particles. While the primary particles were dispersed in zinc borate without any template, these particles were agglomerated in the presence of surface active agents span 60 and PEG 4000.

\section{X-ray Diffraction Analysis (XRD)}

Only a broad peak are observed at $2 \theta$ value of $28^{\circ}$ in X-ray diffraction diagram of the samples indicating that they were amorphous. The small size of the crystals formed in the present study caused broadening of the diffraction lines. The crystal growth occurs in time at high temperature and at high initial concentration and an $\mathrm{x}$-ray diagram with sharp diffraction peaks is obtained. Savrik et al. [2011] obtained sharp diffraction peaks for zinc borate obtained from $1 \mathrm{~mol} \mathrm{dm}^{-3}$ initial concentrations at $70^{\circ} \mathrm{C}$ in two hours. Diffraction peaks for $\mathrm{Zn}\left(\mathrm{B}_{3} \mathrm{O}_{3}(\mathrm{OH})_{5}\right) \mathrm{H}_{2} \mathrm{O}$ (JPDS PDF File Number 721789) were observed by Savrik et al.[ 2011].

\section{The precipitates as lubricant additives}

Previous studies also had shown the lowering of the friction coefficient when zinc borate nanoparticles were added to the base oil [Dong and Hu, 1998, Tian et al, 2006]. The results of the four ball tests are shown for the lubricating oil prepared in the present study. The wear scar diameter for ball 1,2 and 3 are $662 \mu \mathrm{m}, 704 \mu \mathrm{m}$ and $701 \mu \mathrm{m}$ respectively. The average wear scar diameter was $689 \mu \mathrm{m}$.

The change of the friction coefficient with time during the test is 0.079 . The wear scar diameter was lowered from $1402 \mu \mathrm{m}$ to $689 \mu \mathrm{m}$ and the friction coefficient was lowered from $0.099 \mu \mathrm{m}$ to 0.079 by adding nanozinc borate to light neutral oil. The wear scar diameter and friction coefficient was lowered $50 \%$ and $20 \%$ respectively. Compared to inverse emulsion case the friction coefficient was $11 \%$ lower, but the wear scar diameter was $15.6 \%$ higher for the nanozinc borate case.

The visible spectrum of the lubricant before and after four ball tests indicated that the yellow color of the oil was darkened during the tests that was made at $75^{\circ} \mathrm{C}$. The absorbance of the lubricating oil at $414 \mathrm{~nm}$ inceased from 0.06 to 0.84 after the test. This discoloration was due to oxidation and crosslinking reactions in base oil. Thus it is necessary to add antioxidants other than zinc borates to the lubricant to avoid oxidation. 


\section{CONCLUSIONS}

The nano zinc borate particles were prepared in the present study by using low initial zinc and borate concentrations and low temperature to prevent particle growth. The templates span 60 and PEG 4000 has increses the aggregation state of nanoparticles of zinc borate in their mother liquor. The emprical formula of the nanoparticles was approximately $3 \mathrm{ZnO} \cdot 2 \mathrm{~B}_{2} \mathrm{O}_{3} .4 \mathrm{H}_{2} \mathrm{O}$ from EDX analysis. However it could be a mixture of zinc borate and zinc hydroxide. X-ray diffraction diagram indicated the particles were in amorphous state. When the nanoparticles were added to light neutral oil the wear scar diameter and friction coefficient was lowered $50 \%$ and $20 \%$ respectively. However the oil color was darker after the four ball tests indicating addition of antioxidants is necessary. Further studies should be made in synthesis, characterization of zinc borate nano particles and their use in nanoparticle state as lubricant additives and formulating lubricants.

\section{ACKNOWLEDGEMENT}

The authors thank to OPET A.Ş. for four ball tests.

\section{REFERENCES}

Dong, J. X. , Hu Z. S., 1998. A study of the anti-wear and friction-reducing properties of the lubricant additive, nanometer zinc borate, Tribology International 31(5), 219

Eltepe, H. E, Balkose, D. , Ulku S., Effect of temperature and time on zinc borate species formed from zinc oxide and boric acid in aqueous medium. Industrial \& Engineering Chemistry Research, 46(8), 2367

Gonen, M. , Balkose, D.,Gupta R., Ulku S.,2010 Supercritical Carbon Dioxide Drying of Methanol-Zinc Borate Mixtures, Industrial \& Engineering Chemistry Research, 48(14), 68696876.

Gonen, M.,Balkose, D. , Ulku, S., 2011 Supercritical ethanol drying of zinc borates of $2 \mathrm{ZnO} .3 \mathrm{~B}_{2} \mathrm{O}_{3} .3 \mathrm{H}_{2} \mathrm{O}$ and $\mathrm{ZnO} . \mathrm{B}_{2} \mathrm{O}_{3} .2 \mathrm{H}_{2} \mathrm{O}$. Journal of Supercritical Fluids, 59,43

Hu, Z.S., Dong, J.,X., 1998. Study on Antiwear and Reducing Friction Additive of Nanometer Titanium Borate. Wear. 216, 87.

Savrik, S.A., 2010. Enhancement of tribological properties of mineral oil by addition of sorbitan monostearate and zinc borate, PhD Dissertation, Graduate School of Engineering and Sciences of İzmir Institute of Technology

Savrik, S. A, Balkose, D. , Ulku S., 2011. Synthesis of zinc borate by inverse emulsion technique for lubrication, Journal of Thermal Analysis and Calorimetry, 104(2), 605

Tian, Y. M, Y. P. Guo, Y.P., Man Jiang,M., Ye Sheng, Y., Bala H.,B., Guangyu Z.,G.,Yanqiu J, Y., Bing Z., Z., Yanchao Z.,Y., Zichen W.Z.,2006. Synthesis of hydrophobic zinc borate nanodiscs for lubrication Materials Letters 60(20), 2511. 
Atakul Savrik S, Alp B, Ustun F, Balkose D. JOTCSA. 2017; 5(sp. is. 1); 45-52. RESEARCH ARTICLE

Ting, C., D. Jian-Cheng D., Long-Shuo W., Gang, F., 2009. Preparation and characterization of nano-zinc borate by a new method., Journal of Materials Processing Technology, 209(8), 4076

Varlot, K., Kasrai, M., Bancroft, G.M., Yamaguchi, E.S., Ryason, P.R., Igarashi, J.,2001, XRayAbsorption Study of Antiwear Films Generated from ZDDP and Borate Micelles. Wear. 249, 1029-1035. 